\title{
Aspectos BIológicos do ÁcARo Brevipalpus phoenicis Vetor DA Leprose dos Citros em Plantas de BuVa (Conyza canadensis) ${ }^{1}$
}

\author{
Biological Aspects of Brevipalpus phoenicis, a Mite Vector of Citrus Leprosis and Horseweed \\ (Conyza canadensis)
}

\author{
ANDRADE, D.J. ${ }^{2}$, CORREIA, N.M. ${ }^{3}$, BARBOSA, C.L. ${ }^{4}$ e OLIVEIRA, C.A.L. ${ }^{5}$
}

\begin{abstract}
RESUMO - O ácaro Brevipalpus phoenicis, vetor da leprose dos citros, é uma espécie polífaga que tem ampla gama de hospedeiros alternativos nos pomares citricos, nos quais se pode manter e/ou incrementar suas populações. O objetivo deste trabalho foi estudar a sobrevivência, a oviposição e o modo de alimentação do ácaro B. phoenicis em plantas de buva (Conyza canadensis) com diferentes tamanhos. Para avaliação da sobrevivência e oviposição do ácaro B. phoenicis, foi utilizado o delineamento estatístico inteiramente casualizado, com cinco tratamentos e doze repetições. Os tratamentos estudados foram: (1) secções de caules de plantas menores que $20 \mathrm{~cm}$, (2) entre 21 e $50 \mathrm{~cm}$, (3) entre 51 e $100 \mathrm{~cm}$ e (4) maiores que $101 \mathrm{~cm}$ de altura; e (5) secções de ramos de laranja. Dez fêmeas adultas de B. phoenicis, procedentes de uma criação-estoque, foram transferidas para cada secção de caule de buva e ramos de citros como testemunha. Avaliou-se a sobrevivência e a oviposição dos ácaros até 120 horas após a transferência. Alguns aspectos comportamentais do ácaro B. phoenicis foram fotomicrografados, utilizando-se microscópico eletrônico de varredura. Verificou-se que as plantas de maior altura de buva foram mais favoráveis à sobrevivência do ácaro B. phoenicis do que as de menor tamanho. Contudo, a quantidade de ovos postos pelo ácaro não diferiu em relação à altura das plantas de buva. Com base nas fotomicrografias, constatou-se a preferência do ácaro B. phoenicis por se alimentar na base dos tricomas presentes na superficie do caule da planta de buva, justificado, possivelmente, pela maior turgescência das células encontradas nessa região da planta. Esses resultados reforçam a importância do manejo de buva nos pomares cítricos, pois a sua presença no campo pode favorecer a sobrevivência e o desenvolvimento do ácaro B. phoenicis, servindo, portanto, como hospedeira alternativa, o que pode contribuir para a disseminação do ácaro e, consequentemente, da leprose nos pomares cítricos.
\end{abstract}

Palavras-chave: citricultura, oviposição, vírus CiLV.

\begin{abstract}
The mite Brevipalpus phoenicis, vector of citrus leprosis, is a polyphagous species and has a wide host range in citrus orchard, where it can maintain and/or increase its population. The objective of this study was to evaluate some relations between the mite $\boldsymbol{B}$. phoenicis over horseweed plants (Conyza canadensis) for different heights. To determine the oviposition and survival of $\boldsymbol{B}$. phoenicis, an experiment arranged in a complete randomized statistical design was carried out, with five treatments and twelve replications. The treatments established were: (1) plants smaller than $20 \mathrm{~cm}$, (2) plants with height between 21 to $50 \mathrm{~cm}$, (3) plants with height between 51 to $100 \mathrm{~cm}$ and (4) plants taller than $101 \mathrm{~cm}$, as well as (5) branch sections of the orange plant. Ten female adults of $\boldsymbol{B}$. phoenicis were transferred to each section. Survival and oviposition were evaluated 120 hours after transference. The mite was also photomicrographed using a scanning electron microscope. Taller horseweed plants were biased toward B. phoenicis'
\end{abstract}

1 Recebido para publicação em 7.4.2011 e aprovado em 26.8.2011.

2 Doutor em Agronomia (Entomologia Agrícola), Faculdade de Ciências Agrárias e Veterinárias, Universidade Estadual Paulista FCAV/UNESP, Dep. de Fitossanidade, Via de acesso Prof. Paulo Donato Castellane, s/n 14884-970 Jaboticabal-SP, <danieldwv@yahoo.com.br>; ${ }^{3}$ Professora Assistente, Doutora, Dep. de Fitossanidade, FCAV/UNESP, Jaboticabal-SP <correianm@fcav.unesp.br>; ${ }^{4}$ Doutoranda em Agronomia (Entomologia Agrícola), Bolsista CAPES, Dep. de Fitossanidade FCAV/UNESP, Jaboticabal-SP, <crislanyunesp@hotmail.com>; ${ }^{5}$ Professor Titular, Dep. de Fitossanidade, FCAV/UNESP, Jaboticabal-SP. <amadeu@fcav.unesp.br>.

Planta Daninha, Viçosa-MG, v. 30, n. 1, p. 97-103, 2012 
survival, compared to lower plants. However, the number of laid eggs was not different according to horseweed height. Based on the photomicrography, it was possible to verify B. phoenicis 'preference for feeding on the trichome base located on the stem surface of the horseweed. This is possibly justified based on the increased cell turgor in this part. Therefore, the large number of trichomes present in horseweed plants can promote higher survival range and development of B. phoenicis, being thus used as an alternative host, what may contribute to the spread of this mite population and, consequently, of leprosis over the citrus orchards.

Keywords: citrus culture, oviposition, CiLV virus.

\section{INTRODUÇÃO}

O ácaro da leprose dos citros Brevipalpus phoenicis Geijskes (1939) (Acari: Tenuipalpidae) é uma das principais pragas da citricultura por ser vetor do vírus CiLV (Citrus leprosis virus), causador da leprose dos citros, uma das doenças mais graves da citricultura no Brasil (Bastianel et al., 2006). A importância da leprose no Brasil deve-se à sua ocorrência generalizada e aos sérios prejuízos que causa, bem como, especialmente, às dificuldades no manejo, que exige dos pesquisadores e citricultores conhecimentos sobre as relações entre ácaro-vetor, vírus e plantas hospedeiras, influenciadas pelos fatores ambientais (Rodrigues et al., 2003; Welbourn et al., 2003).

O ácaro-vetor da leprose é uma espécie polífaga, tendo ampla gama de hospedeiros alternativos nos pomares cítricos, nos quais se pode manter e/ou incrementar suas populações (Maia \& Oliveira, 2005). Segundo Childers et al. (2003 a, b), o ácaro da leprose é cosmopolita, com ocorrência relatada em 486 espécies de plantas distribuídas em todo o mundo. No Brasil, são conhecidas 47 espécies de plantas daninhas herbáceas que hospedam o ácaro B. phoenicis (Nunes, 2007).

Nos pomares de citros, a manutenção de plantas daninhas deve ser estudada com mais detalhe em termos de época, distribuição e densidade populacional, pois elas podem servir para aumento populacional do ácaro, o qual sai destas para as plantas de citros (Pitelli \& Durigan, 1995). Além disso, Kitajima et al. (2003) e Maia \& Oliveira (2005) ressaltaram a possibilidade de as plantas daninhas comportarem-se como hospedeiras do vírus CiLV, o que representa um risco elevado para os pomares, aumentando sobremaneira a probabilidade de infectar o ácaro e, consequentemente, incrementar a disseminação da leprose.
Maia \& Oliveira (2004), ao avaliarem a capacidade de colonização de $B$. phoenicis em plantas daninhas, verificaram que Bidens pilosa oferece excelentes condições para o desenvolvimento e a sobrevivência do ácaro. Embora as demais plantas avaliadas (Commelina benghalensis, Sida cordifolia e Ageratum conyzoides) tenham sido menos favoráveis ao desenvolvimento do ácaro, elas permitiram a manutenção e o aumento da sua população.

Atualmente, nos cultivos perenes - por exemplo, citros - e nas áreas de grãos sob sistema plantio direto, tem-se constatado aumento na infestação de Conyza canadensis e C. bonariensis, popularmente conhecidas como buva. Esse fato é justificado pelo monocultivo, pelo uso continuado de manejo reduzido do solo, pela ocorrência de resistência devido a aplicações contínuas e frequentes de herbicidas com o mesmo mecanismo de ação (glyphosate, por exemplo), pela falha na aplicação de combinações de herbicidas com mecanismos de ação distintos, pela despreocupação do agricultor quando surgem plantas de Conyza spp. em áreas não cultivadas e pela não adoção de medidas para controlar as infestações durante períodos de pousio (Lazaroto et al., 2008).

O gênero Conyza inclui cerca de 50 espécies, que se distribuem em quase todo o mundo, sendo C. bonariensis e C. canadensis as que mais se destacam, negativamente, nas culturas agrícolas (Kissmann \& Groth, 1999). Childers et al. (2003b) realizaram ampla revisão mundial a respeito das espécies de plantas hospedeiras de ácaros Brevipalpus; entre elas, foram confirmadas plantas de Conyza spp.

Portanto, o objetivo deste trabalho foi estudar a sobrevivência, a oviposição e o modo de alimentação do ácaro $B$. phoenicis em plantas de buva, com reflexos no manejo da leprose em pomares cítricos. 


\section{MATERIAL E MÉTODOS}

O trabalho foi realizado em laboratórios de acarologia e de microscopia eletrônica.

Para estabelecimento da criação-estoque, foram coletados frutos de laranja da variedade Pera infestados com B. phoenicis, em um pomar com cinco anos de idade, sem pulverização de produtos fitossanitários. Escolheramse frutos que, além dos sintomas de leprose, apresentassem sintomas de verrugose, pois o ácaro tem preferência por frutos com superficie irregular (Albuquerque et al., 1997).

No laboratório, os frutos foram lavados com água corrente, secados à sombra e parcialmente parafinados, deixando-se uma área de aproximadamente $10 \mathrm{~cm}^{2}$ sem parafina, que foi circundada com cola entomológica (Cola Tatoo $^{\circledR}$ ) para conter os ácaros. Os frutos foram dispostos em bandejas plásticas e mantidos em câmara climatizada à temperatura de $25 \pm 1{ }^{\circ} \mathrm{C}$, com UR de $70 \pm 5 \%$ e fotofase de 14 horas.

\section{Avaliação da sobrevivência e oviposição -} Plantas de buva e ramos de laranja foram coletados no mesmo pomar cítrico citado anteriormente. Os ramos foram coletados no terço médio das plantas, excluindo-se $20 \mathrm{~cm}$ a partir do ápice de cada ramo. Nas plantas de buva e nos ramos de laranja, foram retiradas com auxílio de estilete secções de $1,5 \mathrm{~cm}$ de comprimento, as quais foram examinadas em microscópio estereoscópico, para eliminação de possiveis ácaros e insetos.
As secções de caule e de ramos foram colocadas em placas de Petri $(9 \times 2 \mathrm{~cm})$ com uma camada de algodão hidrófilo, umedecido diariamente, e nas extremidades de cada secção foi colocada uma fina barreira de cola entomológica $\left(\right.$ Cola Tatoo $\left.{ }^{\circledR}\right)$, para evitar fuga dos ácaros (Figura 1).

Para cada secção foram transferidas dez fêmeas adultas de B. phoenicis, procedentes da criação-estoque, com auxílio de pincel de um pelo e microscópio estereoscópico. Após a transferência, as placas de Petri foram mantidas em câmara climatizada regulada nas mesmas condições citadas para a criaçãoestoque.

O delineamento estatístico foi o inteiramente casualizado, com cinco tratamentos e 12 repetições. Os tratamentos estudados foram estabelecidos em função da altura das plantas de buva: (1) secções de caules de plantas menores que $20 \mathrm{~cm}$, (2) entre 21 e $50 \mathrm{~cm}, 3$ ) entre 51 e $100 \mathrm{~cm}$ e (4) maiores que $101 \mathrm{~cm}$ de altura; e (5) secções de ramos de laranja. Dessa forma, cada secção com dez ácaros foi considerada uma repetição, e em cada placa de Petri foram colocadas quatro secções.

As avaliações foram realizadas $24,48,72$, 96 e 120 horas após a transferência dos ácaros para as secções. Em cada avaliação, foi feita a coleta dos postos e a contagem de ácaros vivos, mortos e retidos na barreira de cola. No cálculo da porcentagem de sobrevivência empregouse a seguinte fórmula: [(número de ácaros

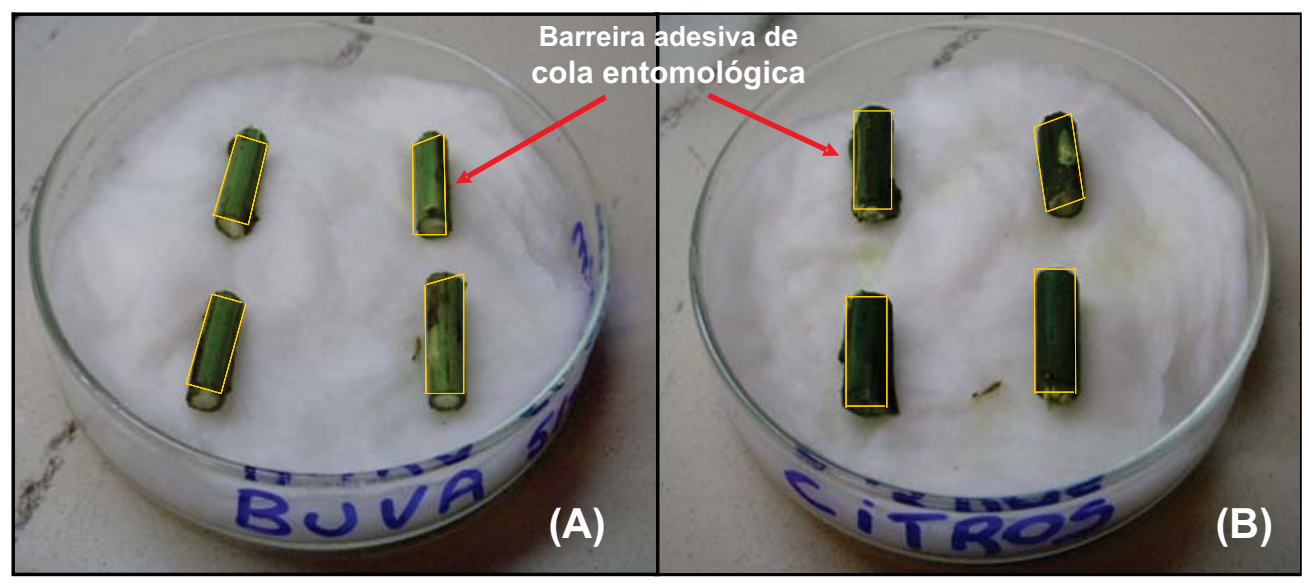

Figura 1 - Placas de Petri contendo algodão hidrófilo e secções de plantas de buva (A) e de laranja (B). 
vivos/número de ácaros vivos + número de ácaros mortos) x 100]. Os dados referentes à sobrevivência e à oviposição média diária foram analisados pelo teste $\mathrm{F}$, e as médias, comparadas pelo teste de Tukey, com $\mathrm{p}>0,05$.

Microscopia Eletrônica de Varredura - A princípio, plantas de buva com $40 \mathrm{~cm}$ de altura foram coletadas, acondicionadas em sacos de papel e encaminhadas ao laboratório. Em seguida, várias secções de caule de buva com $1,5 \mathrm{~cm}$ foram retiradas com auxilio de estilete. Para cada secção de caule, transferiramse com um pincel de um pelo, em média, 30 ácaros $B$. phoenicis procedentes da criaçãoestoque.

Aproximadamente duas horas após a transferência dos ácaros, as secções de ramos foram colocadas em frascos contendo solução de glutaraldeído a 3\%, em tampão de fosfato de potássio a $0,1 \mathrm{M} \mathrm{e} \mathrm{pH} \mathrm{7,4,} \mathrm{por} 72$ horas, para fixação. Em seguida, o material foi colocado em pequenos tubos, com uma malha muito fina nas extremidades, e lavado em solução-tampão pura, para retirada do excesso de fixador. Posteriormente, o material foi pós-fixado em tetróxido de ósmio a $2 \%$, por quatro horas, e depois lavado na mesma solução-tampão citada anteriormente. $\mathrm{Na}$ sequência, procedeu-se a desidratação do material em álcool etílico, secagem em secador de ponto crítico em $\mathrm{CO}_{2} \mathrm{e}$ recobrimento com partículas de ouro (35 nm). Após essas etapas, o material foi preparado sob microscópio estereoscópico para, em seguida, ser elétron-micrografado em microscópio eletrônico de varredura JEOL JSM 5410, operando em $15 \mathrm{kV}$ (Maia \& Santos, 1997).

\section{RESULTADOS E DISCUSSÃO}

Pode-se constatar que, na avaliação realizada 24 horas após a transferência dos ácaros para as secções de caule de buva e ramos de citros, não houve diferenças na sobrevivência dos ácaros (Tabela 1). Todavia, nas avaliações a partir de 48 horas após a transferência houve diferença significativa entre os tratamentos. Os tratamentos com secções de caule de plantas de buva mais altas $(51-100 \mathrm{~cm}$ e $>101 \mathrm{~cm})$ apresentaram porcentagens de sobrevivência estatisticamente semelhantes às do tratamento com ramos de citros, exceto na última avaliação (120 horas), em que o tratamento com a maior altura $(>101 \mathrm{~cm})$ não diferiu do de citros. A maior porcentagem de sobrevivência em ramos de citros era esperada, visto que as plantas cítricas são consideradas excelentes hospedeiras para o desenvolvimento do ácaro B. phoenicis (Ulian \& Oliveira, 2002).

O tratamento com a menor altura de buva $(<$ que $20 \mathrm{~cm}$ ) apresentou a menor porcentagem de sobrevivência de ácaros e diferiu dos demais tratamentos, com exceção do tratamento com altura entre 21 e $50 \mathrm{~cm}$ nas avaliações realizadas 48, 72, 96 e 120 horas após a transferência dos ácaros. A menor sobrevivência nesses tratamentos foi atribuída à presença de uma substância de aspecto brilhante exsudada pelas secções da planta, que ocasionou a morte de ácaros quando estes entravam em contato com ela. Vale ressaltar que a maior quantidade dessa substância foi constatada nas secções de plantas mais jovens (< que $20 \mathrm{~cm}$ ).

Tabela 1 - Valores médios de porcentagem de sobrevivência de fêmeas adultas de Brevipalpus phoenicis, 24, 48, 72, 96 e 120 horas após a transferência para secções de caule de Conyza canadensis e para secções de ramos de citros

\begin{tabular}{|c|c|c|c|c|c|}
\hline \multirow{3}{*}{ 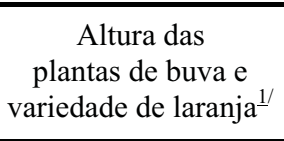 } & \multicolumn{5}{|c|}{ Sobrevivência de ácaros em secções e ramos $(\%)^{\frac{2 /}{1}}$} \\
\hline & \multicolumn{5}{|c|}{ Horas após a transferência dos ácaros } \\
\hline & $24 \mathrm{~h}$ & $48 \mathrm{~h}$ & $72 \mathrm{~h}$ & $96 \mathrm{~h}$ & $120 \mathrm{~h}$ \\
\hline$<20 \mathrm{~cm}$ & $90,8 \pm 3,8 \mathrm{a}$ & $55,8 \pm 6,7 \mathrm{c}$ & $51,3 \pm 7,1 \mathrm{c}$ & $33,7 \pm 7,8 \mathrm{c}$ & $24,7 \pm 7,7 \mathrm{~d}$ \\
\hline $21-50 \mathrm{~cm}$ & $99,2 \pm 3,8 \mathrm{a}$ & $70,4 \pm 6,7 \mathrm{bc}$ & $59,1 \pm 7,1 \mathrm{bc}$ & $51,4 \pm 7,8 \mathrm{bc}$ & $43,3 \pm 7,7 \mathrm{cc}$ \\
\hline $51-100 \mathrm{~cm}$ & $99,2 \pm 3,8 \mathrm{a}$ & $87,6 \pm 6,7 \mathrm{ab}$ & $82,9 \pm 7,1 \mathrm{ab}$ & $73,6 \pm 7,8 \mathrm{ab}$ & $60,4 \pm 7,7 \mathrm{bc}$ \\
\hline$>101 \mathrm{~cm}$ & $99,2 \pm 3,8 \mathrm{a}$ & $95,4 \pm 6,7 \mathrm{ab}$ & $91,6 \pm 7,1 \mathrm{a}$ & $89,8 \pm 7,8 \mathrm{a}$ & $84,3 \pm 7,7 \mathrm{ab}$ \\
\hline Laranja Pera & $100,0 \pm 3,8 \mathrm{a}$ & $97,9 \pm 6,7 \mathrm{a}$ & $98,8 \pm 7,1 \mathrm{a}$ & $98,8 \pm 7,8 \mathrm{a}$ & $96,2 \pm 7,7 \mathrm{a}$ \\
\hline
\end{tabular}

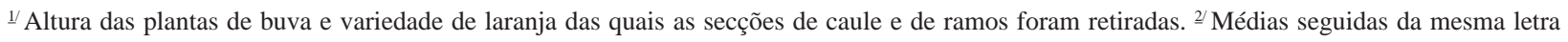
na coluna não diferem entre si. 
Maia \& Oliveira (2004), também, verificaram a presença de uma substância extremamente pegajosa no pedúnculo floral de coroade-cristo (Euphorbia splendens), característica das plantas da família Euphorbiaceae. Possivelmente essa característica tenha sido responsável pela grande mortalidade de ácaros B. phoenicis.

Em relação ao comportamento dos ácaros da leprose transferidos para as secções de caule de buva, foi observado, imediatamente após a transferência, que alguns deles caminhavam para a extremidade dos tricomas presentes na superficie vegetal e ali permaneciam por algum tempo. Esse comportamento pode ter sido em função da necessidade de dispersão do ácaro, uma vez que, provavelmente, a planta de buva não deve ser um hospedeiro preferencial para alimentação dessa espécie.

Esse comportamento de dispersão é característico dos ácaros da família Tetranychidae, os quais procuram as partes periféricas da planta, apoiam sobre as pernas do terceiro e quarto pares e, levantando a parte anterior do corpo e as pernas do primeiro e segundo pares, deixam-se levar pelo vento (Moraes \& Flechtmann, 2008).

Os ácaros, de modo geral, dispersam-se quando a população atinge elevada densidade populacional e/ou quando o substrato não oferece condições adequadas para sua alimentação e abrigo. Contudo, Maia \& Oliveira (2004) relataram que a maior população de ácaros da leprose encontrada em malvavisco, comparado ao hibisco, seja provavelmente devido ao maior número de pelos e às rugosidades presentes na superficie do malvavisco, que podem oferecer maior proteção dos ácaros e dos ovos aos inimigos naturais.

Quanto à oviposição média diária (OMD) do ácaro da leprose, houve diferenças significativas entre os ácaros mantidos sobre buva e citros; a OMD sobre os citros foi de aproximadamente 0,40 [desvio-padrão (DP) = $0,02)$ ] ovos e, sobre buva, de apenas 0,06 ovo $(\mathrm{DP}=0,04)$. Quanto às alturas de plantas de buva, não houve diferenças significativas entre elas (Figura 2).

Maia \& Oliveira (2004), ao estudarem a capacidade de colonização de $B$. phoenicis

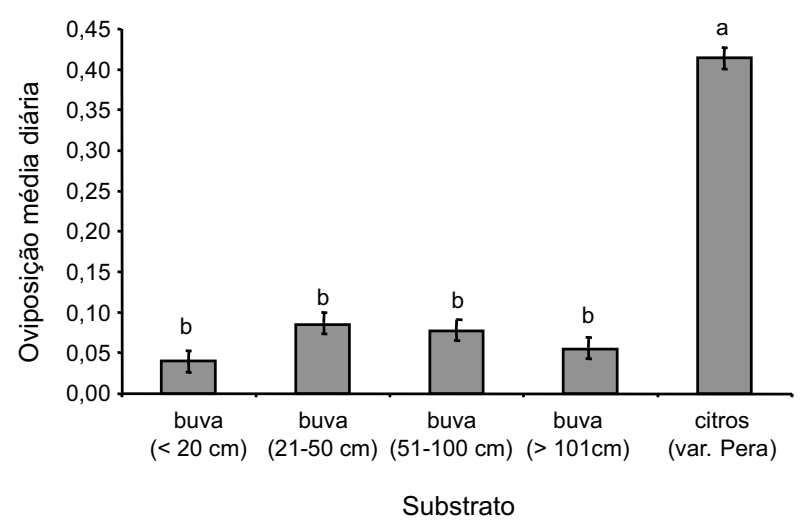

Figura 2 - Oviposição média diária do ácaro Brevipalpus phoenicis mantido sobre secções de caule de Conyza canadensis e sobre ramos de laranja Pera.

em algumas plantas daninhas, constataram que picão-preto ( $B$. pilosa), trapoeraba (C. benghalensis), guanxuma (S. cordifolia) e menstrato (A. conyzoides) proporcionaram condições favoráveis para a oviposição do ácaro da leprose.

No presente trabalho, a alimentação dos ácaros foi preferencialmente na base dos tricomas da buva, onde o tecido vegetal é mais tenro, e a maior quantidade de ovos foi encontrada, principalmente, em pequenas lesões presentes na superficie do caule, tanto na buva como nos citros (Figura 3A). Estudos realizados por Albuquerque et al. (1995) confirmaram a preferência de fêmeas do ácaro $B$. phoenicis por superficies irregulares para realizar postura.

Nesse contexto, Nunes (2007) ressalta a importância das plantas daninhas na epidemiologia da leprose dos citros, pois algumas podem ser hospedeiras muito favoráveis do ácaro da leprose e do vírus CiLV. Dessa forma, devido à importância de Conyza spp. nos pomares de citros, é fundamental a realização de outros estudos a respeito do potencial dessas plantas em hospedar o vírus CiLV e da capacidade do ácaro $B$. phoenicis em adquirir o vírus nas plantas de buva e transmiti-lo às plantas de citros, bem como sobre e a possivel interferência na dinâmica e nas táticas de manejo do ácaro e da doença nos pomares cítricos.

Com base nesses resultados, pode-se confirmar que as plantas mais altas de buva foram mais favoráveis à sobrevivência do ácaro B. phoenicis do que as plantas mais 


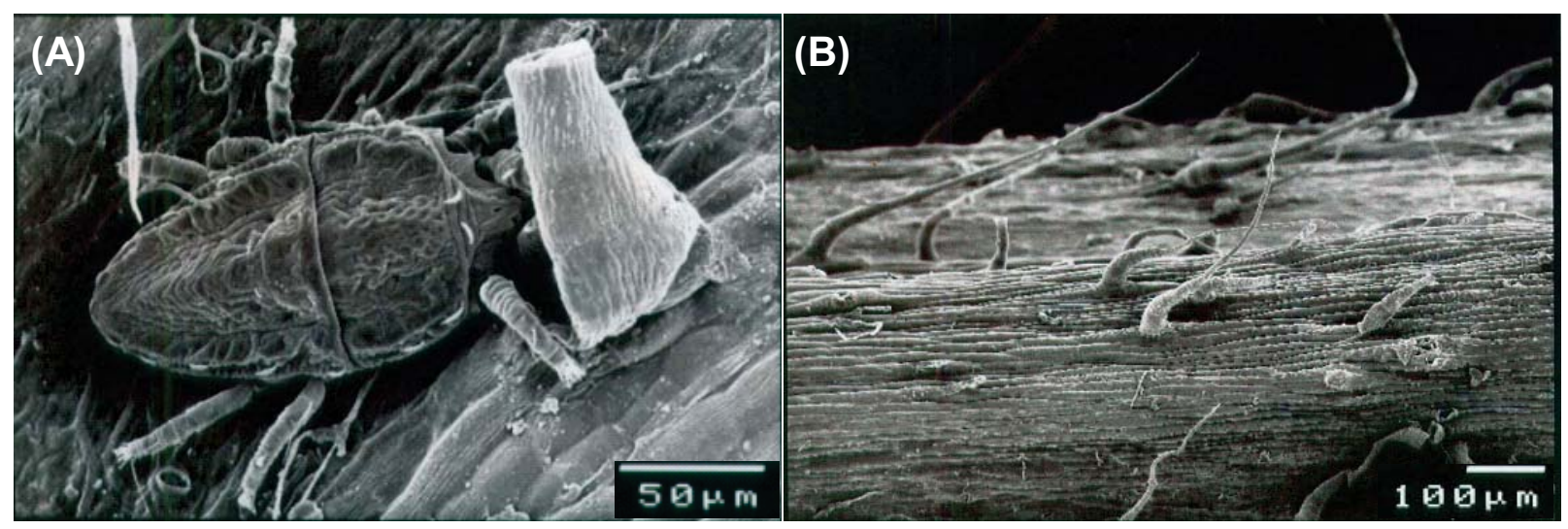

Figura 3 - Eletrón-micrografias de varredura: (A) ácaro Brevipalpus phoenicis sobre Conyza canadensis alimentado na base do tricoma e (B) superfície do caule de $C$. canadensis, com detalhe dos tricomas.

baixas. Entretanto, a quantidade de ovos postos pelo ácaro não diferiu em relação à altura das plantas de buva.

Para que o ácaro fitófago se alimente, é necessário que as células tenham turgescência; com a ação dos seus estiletes, o ácaro perfura as células, para que ocorra o extravasamento do conteúdo celular. A seguir, as bordas do rostro ou os "lábios" formam uma estrutura semelhante a uma ventosa, que permite a sucção do líquido extravasado, com auxílio do vácuo produzido na faringe pela ação de músculos. Vale salientar que os estiletes do ácaro não perfuram feixes de vasos condutores de seiva (Moraes \& Flechtmann, 2008).

As plantas do gênero Conyza possuem grande pilosidade na parte aérea. Essa pilosidade são os tricomas, que podem formar uma densa cobertura e servir de barreira mecânica contra vários fatores externos, como, por exemplo, ataque de pragas e patógenos, radiação ultravioleta, calor extremo e, principalmente, redução da perda de água (Valkama et al., 2003). Entretanto, o papel dos tricomas na redução do ataque de pragas ainda não é totalmente esclarecido, uma vez que os estudos realizados nem sempre levam em consideração as diferenças morfológicas entre os tricomas existentes, bem como o comportamento da praga e de seus inimigos naturais (Figura 3B).

Com base nas fotomicrografias, verificouse a preferência do ácaro B. phoenicis por se alimentar na base dos tricomas presentes na superficie do caule da planta de buva. Esses resultados reforçam a importância do manejo de buva nos pomares citricos, pois a sua presença no campo pode favorecer a sobrevivência e o desenvolvimento do ácaro B. phoenicis, servindo, portanto, como hospedeiro alternativo, o que pode contribuir para a disseminação do ácaro e, consequentemente, da leprose nos pomares cítricos.

\section{LITERATURA CITADA}

ALBUQUERQUE, F. A. et al. Comportamento do ácaro Brevipalpus phoenicis (Geijskes, 1939) (Acari:Tenuipalpidae) em frutos de citros. In: OLIVEIRA, C. A. L.; DONADIO, L. C. (Ed.). Leprose dos citros. Jaboticabal: FUNEP, 1995. p. 77-90.

ALBUQUERQUE, F. A. et al. Estudos da relação entre as incidências de verrugose da laranja doce e leprose dos citros em frutos de laranja-pêra. Científica, v. 25, n. 2, p. 393-402, 1997.

BASTIANEL, M. et al. The citrus leprosis pathosystem. Summa Phytopol., v. 32, n. 3, p. 211-220, 2006.

CHILDERS, C. C. et al. Brevipalpus californicus, B. obovatus, B. phoenicis and B. lewisi (Acari: Tenuipalpidae): a Review of their biology, feeding Injury and economic Importance. Exper. Appl. Acarol., v. 30, n. 1-3, p. 5-28, 2003a.

CHILDERS, C. C. et al. Host plants of Brevipalpus californicus, B. obovatus, and B. phoenicis

(Acari:Tenuipalpidae) and their potential involvement in the spread of one or more viral diseases vectored by these mites. Exper. Appl. Acarol., v. 30, n. 1-3, p. 29-105, 2003b. 
KISSMANN, K. G.; GROTH, D. Plantas infestantes e nocivas. 2.ed. São Bernardo do Campo: Basf, 1999. p. 152-156, 278-284.

KITAJIMA, E. W. et al. Brevipalpus transmitted plant virus and viruslike diseases: cytopathology and reports of some recent cases. Exper. Appl. Acarol., v. 30, n. 1-3, p. 5-28. 2003.

LAZAROTO, C. A. et al. Biologia e ecofisiologia de buva (Conyza bonariensis e Conyza canadensis). Ci. Rural, v. 38, n. 3, p. 852-860, 2008.

MAIA, A. S.; SANTOS, J. M. A SEM technique for preparing biological control agents of nematodes in action. Acta Microscópica, v. 6, SB, p. 550-551, 1997.

MAIA, O. M.; OLIVEIRA, C. A. L. Capacidade de colonização de Brevipalpus phoenicis (Geijskes) (Acari: Tenuipalpidae) em cercas-vivas, quebra-ventos e plantas invasoras. Neotrop. Entomol., v. 33, n. 5, p. 625-629, 2004.

MAIA, O. M.; OLIVEIRA, C. A. L. Transmissibilidade do vírus da leprose de cercas-vivas, quebra-ventos e plantas invasoras para laranjeiras através de Brevipalpus phoenicis (Geijskes). Bragantia, v. 64, n. 3, p. 417-422, 2005.

MORAES, G. J.; FLECHTMANN, C. H. W. Manual de acarologia. Acarologia básica e ácaros de plantas cultivadas no Brasil. Ribeirão Preto: Holos, 2008. v. 1. 288 p.
NUNES, M. A. Transmissão do vírus da leprose dos citros por Brevipalpus phoenicis (Geijskes, 1939) (acari:

Tenuipalpidae) para plantas associadas a pomares cítricos. 2007. 67 f. Tese (Doutorado em Entomologia Agrícola) - Universidade Estadual de São Paulo, Jaboticabal, 2007.

PITELLI, R. A.; DURIGAN, J. C. Manejo de plantas daninhas e controle do ácaro da leprose. In: OLIVEIRA, C. A. L.; DONADIO, L. C. (Ed.). Leprose dos citros. Jaboticabal: FUNEP, 1995. p. 171-178.

RODRIGUES, J. C. V. et al. Citrus leprosis virus vectored by Brevipapus phoenicis (Acari: Tenuipalpidae) on citrus in Brazil. Exper. Appl. Acarol., v. 30, n. 1, p. 161-179, 2003.

ULIAN L. F.; OLIVEIRA, C. A. L. Comportamento do ácaro da leprose dos citros em diferentes cercas-vivas e quebraventos utilizados em pomares cítricos na região de Bebedouro-SP. R. Agric., v. 77, n. 1, p. 103-111, 2002.

VALKAMA, E. et al. Comparative analysis of leaves trichome structure and composition of epicuticular flavonoids in Finnish Birch species. Ann. Bot., v. 91, n. 6, p. 643-655, 2003.

WELBOURN, W. C. et al. Morphological observations on Brevipalpus phoenicis (Acari: Tenuipalpidae) including comparisons with B. californicus and B. obovatus. Exper. Appl. Acarol., v. 30, n. 1, p. 107-133, 2003. 